\title{
How Economists Allocate Time to Teaching and Research
}

\author{
By SAM AllgoOd AND William B. WALSTAD*
}

* Department of Economics, University of Nebraska-Lincoln, Lincoln, NE 68588-0489. (e-mails: sallgood1@unl.edu; wwalstad1@unl.edu).

Forty years ago a paper that focused on how teaching performance and research output affected the salaries of academic economists was published in this journal (Siegfried and White 1973a). ${ }^{1}$ The study raised significant questions about how institutional incentives or reward structures for economics professors influence the faculty allocation of time to teaching and research (Weisbrod 1978). That line of research on academic economists has evolved in different ways as shown in articles published in the past decade (e.g., Moore, Newman, and Turnbull 2001; Becker and Kennedy 2005; Walstad and Allgood 2005; Taylor, Fender, and Burke 2006).

This study extends our previous research on the topic using a new national dataset to analyze three primary questions: (1) Do economists differ in their teaching and research behavior from professors in related disciplines? (2) Are the determinants of time allocated to teaching and the time allocated to research different for economists than for

\footnotetext{
${ }^{1}$ For related version, see Siegfried and White (1973b).
}

other professors? (3) Do professors respond differently to changes in incentives in allocating their time? We compare the allocation of time to teaching and research for economics professors at research or doctoralgranting institutions with that of faculty members in five other disciplines: math, physics, psychology, political science and business. We also analyze the time allocation data by whether or not the individual departments are in the top 100 research departments in their discipline. Finally, we specify regression equations to explain time allocations for teaching and research and control for the effects of institutional incentives for teaching and tenure.

\section{Data and Sample}

The National Study of Postsecondary Faculty (NSOPF) for 2003-2004 was a webbased survey administered by the National Center for Education Statistics. Data were collected in 2004, with faculty members asked to respond based on their activities in the previous academic year. Although survey data from educational institutions were collected separately from the faculty survey, the coding 
of the two surveys permitted data from each one to be merged. The total sample contained survey responses from over 35,000 faculty members and institutional data from 1,080 not-for-profit colleges and universities. ${ }^{2}$

For this study, a number of restrictions were placed on the data to create a sample of professors performing similar jobs at similar institutions. First, only professors at research or doctoral institutions, as classified by the Carnegie Foundation, were included in the sample. Second, the university had to have a tenure system for faculty selection and promotion. Third, the faculty members had to be full-time employees on a tenured or tenuretrack line, with a rank of assistant, associate, or full professor. As a consequence of this restriction, academic administrators were excluded from the study because they allocate time differently than regular faculty members given their other responsibilities. Fourth, the professors must have taught at least one class with their compensation based on a standard contract for the academic year.

The fifth restriction was a major one that limited the sample to particular academic disciplines. Of course, economics was included in the sample because the central purpose of the study was to investigate how

\footnotetext{
2 Survey documentation and other information are available at http://nces.ed.gov/surveys/nsopf/index.asp.
}

economists differ from professors in other disciplines. The selection of the five other disciplines for the sample was based on their overlap with economics either because of their commonalities with analytical methods or proximities with academic departments within a university. Economics makes extensive use of mathematical analysis so in this respect its approach to academic study is similar to that used in math and physics. Economics has long been listed as one of the social sciences, which together with its origins in the study of political economy gives it an affinity with political science. In more recent years, economics has focused on the study of human behavior using data from natural and field experiments, so there is a direct connection to psychology. Finally, economics departments can be housed in business colleges that typically also include accounting, finance, management, and marketing departments. The two business departments most similar in their extensive use of quantitative analysis as economics would be finance and accounting.

The above rationale was used to select the six disciplines for the study. The final sample consisted of 1,000 professors who taught at 390 universities. The breakdown by discipline shows 12.7 percent in economics, 24.3 percent in math, 10.5 percent in physics, 13.1 percent 
in political science, 24.8 percent in psychology, and 14.7 percent in business. ${ }^{3}$

The sample is similar across disciplines on many characteristics. The mean age of the professors is 49 years old with little variation by discipline. Thirty percent of the sample are associate or full professors and forty percent are assistant professors. This division holds across the disciplines except in physics where about half are assistant professors. A third of the sample teach at private institutions, but no discipline has more than 38 percent at private institutions. Twenty percent of the professors teach at universities rated among the top 100 based on research rankings, which is comparable across the other disciplines. ${ }^{4}$

Other variables reveal more variation by discipline, but the differences are not unique to a discipline or extreme across disciplines. A quarter of the sample is female, although it falls to 15-18 percent in economics, physics, political science, and math. Thirteen percent of the sample is non-white, but it is 9 percent in economics and 3-4 percent in psychology and political science. The universities where

\footnotetext{
3 All sample statistics that follow are computed using sampling weights provided for the NSOPF. Business is only represented by finance and accounting, which were combined for this analysis because there were too few observations for a separate analysis of each group.

4 http://ww.aeaweb.org/gradstudents/Rankings.php; political science (Hix 2004); math, physics, psychology, and accounting http://ww.yuaccounting.net/rankings/univrank/custom_rank_rpt.php; finance:http://wpcarey.asu.edu/fin-rankings/rankings/results.cfm.
}

these faculty members teach enroll about 16,000 students, on average, with business professors teaching at slightly larger schools $(17,760$ students) and math professors teaching at slightly smaller schools $(15,240$ students). The average monthly salary is $\$ 7,400$. Business professors earn the most $(\$ 8,989)$ followed by physics professors $(\$ 8,274)$ and economics professors $(\$ 8,200)$.

Table 1 shows time allocations and teaching loads for professors. The mean for the total hours worked per week (TotTime) is 54.2. The professors who report fewer hours worked than the mean were in math $(-2.8)$, business $(-2.0)$ and economics (-0.9). Professors reporting more than the mean hours worked per week were in psychology $(+2.0)$, political science (+2.1) and physics (+2.7).

TABle 1 - Time Allocations AND TEACHING LOAD

\begin{tabular}{lrrrrrrr}
\hline \hline & Econ & Bus & Physics & Math & Psych & PolSci & Total \\
\hline TotTime & 53.3 & 52.2 & 56.9 & 51.4 & 56.2 & 56.3 & 54.2 \\
TchTime & 28.6 & 29.4 & 31.5 & 31.1 & 31.1 & 30.6 & 30.5 \\
ResTime & 15.3 & 14.8 & 16.6 & 12.0 & 14.1 & 13.9 & 14.1 \\
OthTime & 5.2 & 5.5 & 6.5 & 5.7 & 6.2 & 7.5 & 6.0 \\
ExtTime & 4.2 & 2.5 & 2.3 & 2.6 & 4.8 & 4.3 & 3.6 \\
\#Classes & 2.6 & 2.8 & 2.2 & 2.7 & 2.7 & 2.9 & 2.7 \\
\#Students & 90.5 & 91.8 & 53.9 & 80.9 & 85.1 & 110.8 & 85.8 \\
LargeClass & 0.07 & 0.01 & 0.05 & 0.05 & 0.11 & 0.12 & 0.07 \\
\hline
\end{tabular}

The professors were asked what percentages of their work hours were devoted to teaching (TchTime), research (ResTime), other duties within the institution (OthTime), and work on jobs outside the institution (ExtTime). As for teaching, economics professors spend only 28.6 hours on it, which is 2.0 to 2.9 hours less per week than professors in the other 
disciplines except business, for which the difference with economics is minor (0.8). As for research, the opposite is the case. Economics professors spend more time on research than all other faculty members, with the exception of physics professors, who spend 1.3 hours more per week on it than economists. The difference is greatest when the comparison is made with professors in psychology $(+1.2)$, political science $(+1.2)$, and math (+3.0). As for other or extra work, the two offset each other. Economists spend slightly less time, on average, on duties inside the institution $(-0.8)$, as do business and math professors, and slightly more time, on average, on jobs outside the institution $(+0.6)$ as do psychology and political science professors.

The teaching load of economics professors ( 2.6 classes) is about the same as the 2.7 to 2.9 classes taught by professors in four of the five other disciplines. Economics professors teach an average of 91 students, a number that is about the same as business professors, less than political science professors, and greater than professors in physics, math, and psychology. The discipline that is most different from the others on teaching matters is physics. Physics professors report the smallest teaching load (2.2) and teach significantly fewer students (53.9). They also spend more time teaching each class (15 hours) than do the professors in the other disciplines, including economics (11 hours).

One final item of difference to note relates to large classes. Seven percent of economics professors report teaching a class of at least 100 students, a percentage which is average for the sample. It ranges, however, from a low of one percent in business to five percent in physics and math to 11 or 12 percent in psychology and political science. Apparently, the social sciences are most willing to use large class instruction perhaps because of high enrollments or to minimize teaching loads.

Although the sample is restricted to faculty members employed at research and doctoralgranting institutions, teaching time and loads differ across institutions based on research ranking. For this purpose, the sample was split into two groups, one for faculty members employed at the top 100 departments and the other for professors at institutions ranked lower in research output. Table 2 shows the comparison between the top 100 and other professors on teaching time and class load.

TABLE 2-TOP 100 VERSUS OTHER

\begin{tabular}{llccc}
\hline \hline & \multicolumn{2}{c}{ Teach Time } & \multicolumn{2}{c}{ \#. of classes } \\
& Other & Top 100 & Other & Top 100 \\
\hline Economics & 30.5 & 22.2 & 2.8 & 2.1 \\
Business & 30.4 & 26.4 & 2.9 & 2.6 \\
Physics & 33.3 & 23.9 & 2.9 & 1.8 \\
Math & 32.7 & 25.9 & 2.9 & 1.7 \\
Psychology & 32.1 & 29.5 & 2.3 & 1.3 \\
Pol. Science. & 31.5 & 25.6 & 3.0 & 2.1 \\
\hline
\end{tabular}

In the top 100 departments, economics professors devote eight hours less per week to 
teaching than economists at other institutions, but economists in the top 100 departments only teach an average of 2.1 classes compared with the 2.8 classes taught by economists at other institutions. The hours spent per class on teaching, however, are about identical for the two groups of economists (10.6 and 10.9).

Comparisons across disciplines show that economists in the top 100 departments spend fewer hours on teaching than professors in top departments in four of five disciplines $(-1.7$ hours compared with physics to -7.3 hours compared with psychology). The fewer hours devoted to teaching come despite class loads that are generally higher for economists.

\section{Model and Results}

A regression equation was specified and estimated to explore factors associated with both time spent by professors on teaching (Teach) and research. The dependent variables for time were measured in logs and the equations were estimated with OLS. Dummy variables were included to control for the demographic factors such as gender (Female), race (NonWhite), rank (FullProf, AssocProf), and the public or private oversight of the university (Private). Two other variables included were the log of the monthly wage (LogWage) and the total number of students enrolled at a university (TotEnroll).
Five variables were added to the regressions to control for teaching factors. The first three were the $\log$ of the number of classes taught (LogClasses), the $\log$ of the number of students taught (LogStudent), and a dummy variable for whether a professor taught a large class. Teaching incentives were measured by two dummy variables. TchAssess was coded one if professors reported that their institution used test scores, career placement, or other measures of student performance to assess teaching. TchReward was coded one if professors strongly agreed that "good teaching is rewarded" at their university.

Four variables were added to the regressions to assess the influence of research activity and incentives. The research intensity of faculty members was measured by Pubs/Year, which equaled the number of refereed articles published over an academic career, minus the number published in the past two years, with the total divided by the number of years since the faculty member earned a Ph.D. degree. Pubs/Year was set to zero for those with two or less years since earning a Ph.D. The Top 100 variable was the research ranking of the academic department of professors. The effects of research incentives were captured with two variables created from the institution survey. The difficulty of obtaining tenure is reflected in PerTenured (the number of faculty 
granted tenure during an academic year divided by the number considered for tenure at an institution). The survey also asked if institutions raised tenure standards in the last five years. UpStandard is used to evaluate this change on teaching and research. The last five items in the regressions were variables to control for disciplines (economics omitted).

The results for the sample of 1,000 professors are reported in Table 3. Academic rank shows the most notable association with teaching and research among the demographic variables. Full professors spent a significant 20 percent more time on research than do assistant professors, perhaps because a research agenda expands over a career. Although full professors spend six percent less time on teaching than assistant professors, the difference is minor. Associate professors too spend more time on research ( 7 percent) and less time on teaching (11 percent) than assistant professors, but the difference is only significant for teaching.

As for the effects of the teaching variables on teaching time, the main results show three outcomes. The elasticity of teaching time with respect to number of classes taught is relatively small at 0.19 , but statistically significant. Incentives seem to matter because the two incentive variables for teaching are also statistically related to teaching time.
Professors who report that teaching is rewarded at their institutions spend 12 percent more time teaching. In addition, professors who state that some type of performance measure is used to assess teaching spend 5 percent more time teaching.

\begin{tabular}{lcclcc}
\multicolumn{7}{c}{ TABLE 3-RESULTS } \\
\hline \hline \multirow{5}{*}{ Teach } & Research & Teach & Research \\
\hline Female & 0.038 & -0.118 & TchReward & 0.121 & -0.048 \\
& $(1.13)$ & $(1.53)$ & & $(4.17)$ & $(0.70)$ \\
Nonwhite & -0.036 & 0.062 & Pubs/Year & -0.021 & 0.118 \\
& $(0.82)$ & $(0.84)$ & & $(1.64)$ & $(5.89)$ \\
FullProf & -0.064 & 0.199 & Top100 & -0.104 & 0.226 \\
& $(1.54)$ & $(2.23)$ & & $(2.21)$ & $(2.91)$ \\
AssocProf & -0.111 & 0.070 & PerTenured & 0.049 & -0.243 \\
& $(2.79)$ & $(0.87)$ & & $(0.54)$ & $(1.65)$ \\
LogWage & -0.086 & 0.171 & UpStandard & -0.018 & 0.141 \\
& $(1.98)$ & $(1.45)$ & & $(0.39)$ & $(1.87)$ \\
Private & 0.006 & -0.063 & Bus & 0.033 & 0.039 \\
& $(0.15)$ & $(0.77)$ & & $(0.59)$ & $(0.36)$ \\
TotEnroll & -0.002 & 0.006 & Math & 0.083 & -0.304 \\
& $(0.99)$ & $(1.70)$ & & $(1.80)$ & $(3.02)$ \\
LogClasses & 0.194 & -0.740 & Psych & 0.047 & -0.115 \\
& $(3.79)$ & $(9.38)$ & & $(0.90)$ & $(1.04)$ \\
LogStudent & 0.500 & -0.008 & Physics & 0.246 & -0.363 \\
& $(1.47)$ & $(0.17)$ & & $(4.32)$ & $(2.79)$ \\
LargeClass & -0.034 & 0.120 & PolSci & -0.003 & 0.127 \\
& $(0.50)$ & $(1.01)$ & & $(0.05)$ & $(1.13)$ \\
TchAssess & 0.052 & -0.039 & Constant & 3.719 & 1.467 \\
& $(1.73)$ & $(0.64)$ & Adj. R & 0.177 & 0.337 \\
\hline
\end{tabular}

The research time equation also reveals variable effects, but as might be expected they are not the same set of variables that affect teaching. Research intensity does show the expected positive and statistically significant effect on research time, but its negative effect on teaching is insignificant. The elasticity of research time with respect to number of classes taught is relatively large at -0.74 , suggesting that a change in teaching load will significantly affect time spent on research. The tenure policy also matters. The larger the fraction of faculty members awarded tenure at an institution from the pool considered, the 
less time that professors spend on research. Professors also spend 14 percent more time on research if they work at an academic institution that has raised their tenure standards in the last five years.

After controlling for teaching factors and research intensity, the research status of a department makes a difference to teaching and research time. Professors in the top 100 departments spend 23 percent more time on research and 10 percent less time on teaching than professors in lower-ranked departments.

Finally, the results show some differences among economics and the other disciplines, but they are relatively minor. Economists devote significantly more time (30 or 36 percent) on research than do math and physics professors and economists also spend significantly less time ( 8 or 25 percent) on teaching than math and physics professors. No other noteworthy differences were found among economics and the other disciplines.

\section{REFERENCES}

Becker, William E. and Peter Kennedy. 2005. "Does Teaching Enhance Research in Economics?" American Economic Review, 95(2): 172-76.

Hix, Simon. 2004. "A Global Ranking of Political Science Departments." Political Studies Review, 2(3): 293-313.
Moore, William J., Robert J. Newman, and

Geoffrey K. Turnbull. 2001. "Reputational Capital and Academic Pay." Economic Inquiry, 39(4): 663-71.

Siegfried, John J., and Kenneth J. White. 1973a. "Financial Rewards to Research and Teaching: A Case Study of Academic Economists." American Economic Review, 63(2): 309-16.

Siegfried, John J., and Kenneth J. White. 1973b. "Teaching and Publishing as Determinants of Academic Salaries." Journal of Economic Education, 4(2): 9099.

Taylor, Susan W., Blakely F. Fender, and Kimberly G. Burke. 2006. "Unraveling the Academic Productivity of Economists: The Opportunity Costs of Teaching and Service." Southern Economic Journal, 72(4): 846-59.

\section{Walstad, William B. and Sam Allgood.} 2005 "Views of Teaching and Research in Economics and Other Disciplines." American Economic Review, 95(2): 177-83.

Weisbrod, Burton A. 1978. "Research in Economic Education: Is It Asking the Right Questions?" American Economic Review, 69(2): 14-21. 